\title{
Synthesis and Characterization of Novel Catalytic Materials Using Industrial Slag: Influence of Alkaline Pretreatment, Synthesis Time and Temperature
}

\author{
Ekaterina Kholkina ${ }^{1} \cdot$ Narendra Kumar $^{1} \cdot$ Taina Ohra-aho $^{2} \cdot$ Juha Lehtonen $^{2} \cdot$ Christian Lindfors $^{2} \cdot$ Marcus Perula $^{3}$. \\ Janne Peltonen ${ }^{3} \cdot$ Jarno Salonen $^{3} \cdot$ Dmitry Yu. Murzin $^{1}$ (D)
}

Published online: 21 March 2019

(c) The Author(s) 2019

\begin{abstract}
Industrial ferrous wastes found their application in construction. However, they are mostly stored polluting the environment. In the current work, possibility of value added products synthesis from steel slag with their further use as catalysts was investigated. Slag-based catalysts were obtained by alkaline treatment with sodium hydroxide by variation of synthesis parameters. The physico-chemical properties of the synthesized materials were determined by $\mathrm{N}_{2}$-physisorption, SEM, EDX, TEM, XRD and TPD. Slag-based catalysts were applied in the transformation of wood biomass, namely softwood sawdust. Novel catalytic materials synthesized from industrial slag exhibited the presence of strong basic sites and highly crystalline phases of $\mathrm{SiO}_{2}, \mathrm{Al}_{2} \mathrm{O}_{3}, \mathrm{CaCO}_{3}, \mathrm{Ca}(\mathrm{OH})_{2}, \mathrm{Fe}_{2} \mathrm{O}_{3}, \mathrm{MgO}$ and $\mathrm{TiO}_{2}$. Alkaline treatment of the raw material promoted creation of mesoporosity and an increase of the surface area. Catalytic fast pyrolysis of pine sawdust displayed variations in the yields of the reaction products in the presence of catalysts as compared to thermal fast pyrolysis.
\end{abstract}

\section{Graphical Abstract}

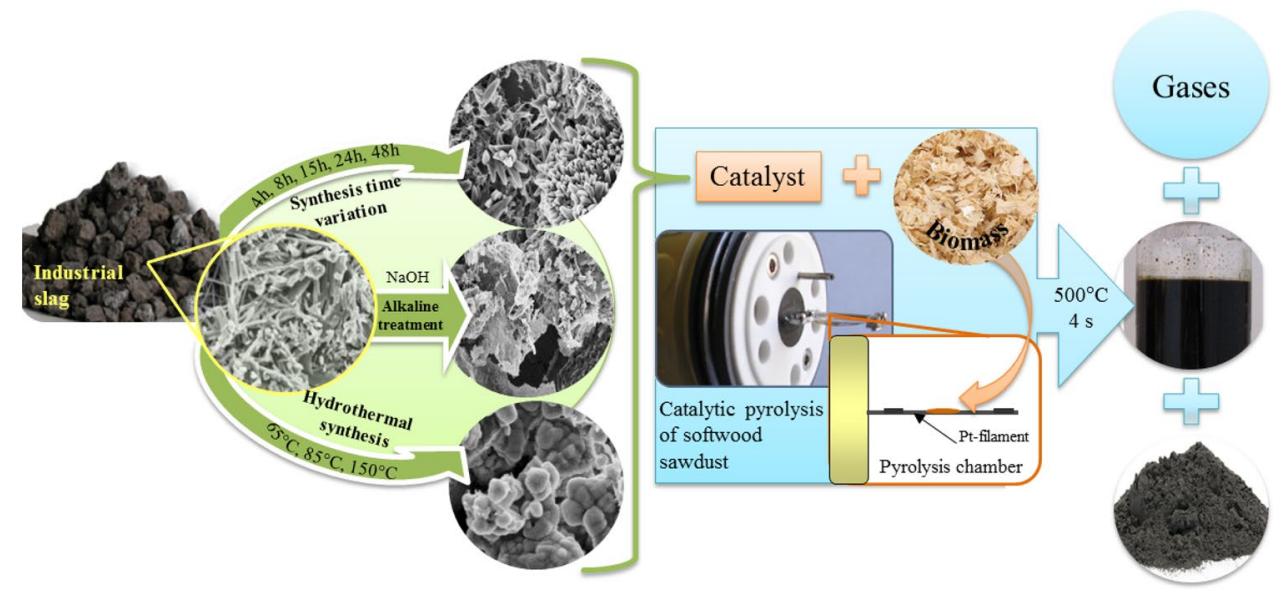

Keywords Slag-based catalysts $\cdot$ Alkaline synthesis $\cdot$ Hydrothermal synthesis $\cdot$ Catalyst characterization $\cdot$ Pyrolysis of biomass

Dmitry Yu. Murzin

dmurzin@abo.fi

Extended author information available on the last page of the article

\section{Introduction}

Studies on utilization and upgrading of solid residual materials from bulk chemical, petro-chemical, metallurgical, steel and nuclear industry are gaining importance for both academia and 
industry. The issue of slag recycling from pyrometallurgical processing of natural ores attracts attention of many scientists in connection with a possibility of converting slags in to valueadded products and reduction waste [1].

Ferrous slag, a by-product of complex and diverse chemical composition, is produced during recovery of iron from the ores (blast furnace slag (BFS)) or recycled materials in the process of steel manufacturing [2]. A typical composition of ferrous slags presented in Table 1 is dominated by $\mathrm{Ca}$ and $\mathrm{Si}$ with variable amounts of $\mathrm{Al}, \mathrm{Fe}$ and $\mathrm{Mg}$. The other major elements are $\mathrm{K}, \mathrm{Na}$ and Ti with average amounts lower than $2 \mathrm{wt} \%[3,4]$.

Slag is applied in specialized market sectors. According to the European association of manufacturing and utilization of ferrous slag products (EUROSLAG), industrial slags found their predominant application in different fields such as road construction [6-8], cement production [9-12] and can be also used as heat carriers [13].

An interest in utilization of industrial slags in the synthesis of catalysts has been recently increased. Dimitrova et al. [14] reported a possibility of utilizing BFS as a support of metals $(\mathrm{Cu}, \mathrm{Co}, \mathrm{Mn}$ and $\mathrm{Ni})$ in the synthesis of catalysts for carbon monoxide and benzene oxidation. Utilization of iron slag was performed in the synthesis of $\mathrm{Ni}$ catalyst by $\mathrm{Yu}$ et al. [15]. BFS, containing $\mathrm{MgO}, \mathrm{CaO}, \mathrm{Fe}_{2} \mathrm{O}_{3}, \mathrm{SiO}_{2}$, and $\mathrm{Al}_{2} \mathrm{O}_{3}$, which are common components in biomass pyrolysis catalysts, was used as a support for synthesis of a Ni-based catalyst for pyrolysis of pine sawdust. It was shown that application of BFS helps in the inhibition of coke deposition during catalytic pyrolysis of biomass due to presence of the basic elements in the slag such as $\mathrm{Ca}$ and $\mathrm{Mg}$. A possibility of using BFS in catalytic cracking processes was proposed by Kar and Gürbüz [16]. A low-cost slag catalyst was used for the catalytic cracking of used frying sunflower oil. Due to a high $\mathrm{CaO}$ content, $\mathrm{BFS}$ was beneficial for the cracking process allowing a higher yield (ca. 84 wt.\%) in comparison with pure $\mathrm{CaO}$ (ca. 75 wt.\%).

Steel slag was applied as a catalyst in glycerol transesterification with dimethyl carbonate giving $97 \%$ yield of glycerol carbonate as the desired product [17]. Modification of industrial slag was performed using sodium hydroxide with various concentration (1-15 wt.\%).

The main purpose of this research was synthesis of slagbased materials, which can be used as catalysts in fast pyrolysis of biomass. Therefore, there was a need not only to increase the surface area of the synthesized catalysts, but also to create active sites. It is also important to obtain a mesoporous structure for facilitating access of the reactants to the internal catalytic surface.

Alkaline pretreatment as one of the ways of treatment is a well-known procedure of desilication, promoting formation of the mesoporous structure [18-21]. In contrast to the acid treatment, alkaline treatment promotes selective extraction of framework Si atoms with creation of uniform-sized mesopores without changes in the crystallinity $[18,19]$. Formation of mesopores and a significant increase of the surface area were observed during the alkaline treatment of zeolites [20, 21].

The use of industrial slags as a source for the synthesis of catalytic materials results in a significant decrease in the catalyst costs. Another positive impact for the production of slag-based catalysts is the environmental impact, namely recycling of industrial waste.

This work was focused on synthesis of the catalytic materials from industrial steel slag by the alkaline treatment. Influence of synthesis parameters (alkaline solution concentration, synthesis temperature and time) on textural, structural and catalytic properties of raw steel slag as well as synthesized slag-based materials was explored.

\section{Experimental}

\subsection{Catalyst Preparation}

In this work, catalytic materials were synthesized using desulfurization steel slag containing $\mathrm{SiO}_{2}, \mathrm{Al}_{2} \mathrm{O}_{3}, \mathrm{FeO}, \mathrm{CaO}$ and other minor components. Industrial slag was provided by SSAB, Finland. The used slag was crushed by ball milling and sieved to the desired fraction $(<90 \mu \mathrm{m})$.

Catalytic materials were obtained by alkaline pretreatment with $\mathrm{NaOH}$ solution varying such synthesis parameters as concentration of the alkaline solution, synthesis temperature and time.

\subsubsection{Effect of Alkaline Solution Concentration}

In a typical experiment of alkaline pretreatment with variation of an alkaline solution concentration, $7 \mathrm{~g}$ of the ball-milled material was mixed with $300 \mathrm{ml}$ of the $\mathrm{NaOH}$ solution of different molarity $(0.6 \mathrm{M}, 1 \mathrm{M}$ and $2 \mathrm{M})$ with a constant stirring and under $\mathrm{pH}$ control during $4 \mathrm{~h}$.
Table 1 The average concentration of the main oxides for the BFS and steel making slag [5]

\begin{tabular}{llllllllll}
\hline Constituent & $\mathrm{CaO}$ & $\mathrm{SiO}_{2}$ & $\mathrm{Al}_{2} \mathrm{O}_{3}$ & $\mathrm{MgO}$ & $\mathrm{FeO}$ & $\mathrm{MnO}$ & $\mathrm{P}_{2} \mathrm{O}_{5}$ & $\mathrm{~S}_{\text {total }}$ & $\mathrm{Cr}_{2} \mathrm{O}_{3}$ \\
\hline BFS, wt.\% & $35-42$ & $33-38$ & $10-15$ & $7-12$ & $\leq 0.1$ & $\leq 0.1$ & - & $1-1.5$ & $\leq 0.1$ \\
$\begin{array}{c}\text { Steel making } \\
\text { slag, wt.\% }\end{array}$ & $35-45$ & $11-17$ & $1-6$ & $2-9$ & $16-26$ & $2-6$ & $1-2$ & $\leq 0.2$ & $0.5-2$ \\
\end{tabular}




\subsubsection{Influence of Synthesis Time}

A typical experiment of alkaline pretreatment with variation of the synthesis time $(4,8,15,24$ and $48 \mathrm{~h})$ was carried out using $0.6 \mathrm{M} \mathrm{NaOH}$ solution at ambient conditions according to the procedure described in Sect. "2.1.1".

\subsubsection{Influence of Synthesis Temperature (Hydrothermal Synthesis)}

Hydrothermal synthesis of industrial slag was carried out using tumbling reactors $(300 \mathrm{ml})$ placed in a furnace. The synthesis was carried out at 65,85 and $150{ }^{\circ} \mathrm{C}$ for $4 \mathrm{~h}$ using $0.6 \mathrm{M} \mathrm{NaOH}$ solution as the treating agent. In a typical experiment, $4 \mathrm{~g}$ of the ball-milled slag was mixed with $175 \mathrm{ml}$ of $\mathrm{NaOH}$ solution in a Teflon cup, which was placed in the autoclave. The system was sealed and placed in an oven heated to the desired temperature. At the end of the predetermined period of time the system was cooled under ambient temperature.

All catalysts were filtered on a Büchner funnel and washed with distilled water followed by drying at $100{ }^{\circ} \mathrm{C}$ for $7 \mathrm{~h}$ and calcining at $400{ }^{\circ} \mathrm{C}$.

\subsection{Catalyst Characterization}

The characterization of the slag-based catalysts was carried out using nitrogen physisorption, SEM, EDXA, TEM, TPD- $\mathrm{NH}_{3}$ and TPD-CO ${ }_{2}$, and XRD, as described below.

\subsubsection{Nitrogen Physisorption Method}

$\mathrm{N}_{2}$ physisorption was applied to determine the specific surface area, pore volume and pore size distributions of the synthesized materials. Measurements were carried out using Carlo Erba Soptomatic 1900 Instruments applying the Dubinin method for determination of the surface area of microporous materials. Pore volume calculations were performed using the Horvath and Kawazoe method. The slag catalysts were evacuated at $150{ }^{\circ} \mathrm{C}$ for $3 \mathrm{~h}$ prior to the measurements.

\subsubsection{Scanning Electron Microscopy}

Scanning electron microphotographs of the synthesized materials were obtained with a LEO Gemini 1530 Scanning electron microscope with a Thermo Scientific UltraDry Silicon Drift Detector (SDD). In the current work, SEM was used to study the morphology, shape, size and distribution of crystals of the catalysts. EDX was performed to determine the elemental composition.

\subsubsection{Transmission Electron Microscopy}

Transmission electron microscopy characterization was designed to study the structure, porosity, metal particle size and channel systems. Measurements were made with a JEM1400 Plus with $120 \mathrm{kV}$ acceleration voltage and resolution of $0.38 \mathrm{~nm}$ equipped with OSIS Quemesa 11 Mpix bottom mounted digital camera.

\subsubsection{Temperature Programmed Desorption}

Temperature programmed desorption measurements were carried out with Micromeritics AutoChem 2910 instrument equipped with a thermal conductivity detector (TCD) using $\mathrm{NH}_{3}\left(\mathrm{TPD}-\mathrm{NH}_{3}\right)$ and $\mathrm{CO}_{2}\left(\mathrm{TPD}-\mathrm{CO}_{2}\right)$ as probe molecules for determination of the presence, amount and strength of acid and basic sites, respectively.

\subsubsection{X-ray Powder Diffraction}

$\mathrm{X}$-ray powder diffraction analysis was performed using monochromatized $\mathrm{Cu}-\mathrm{K}_{\alpha}$ radiation (Philips X'Pert Pro MPD) with a voltage of $40 \mathrm{kV}$ and a current of $45 \mathrm{~mA}$. The primary $\mathrm{X}$-ray beam was collimated with a fixed $0.25^{\circ}$ divergence slit and a fixed $10 \mathrm{~mm}$ mask. A $7.5 \mathrm{~mm}$ anti-scatter slit was used in the diffracted beam side prior to the proportional counter. The samples were ground gently before the measurements to minimize the sample texture (preferred crystal orientation). Copper sample holders were used.

\subsection{Catalytic Tests}

Synthesized slag-based catalysts were tested in analytical fast pyrolysis using softwood sawdust as a biomass feedstock. The pyrolysis set-up consisted of a filament pulse pyrolyzer (Pyrola2000, PyrolAB, Sweden), which was connected to a gas chromatograph (Agilent 7890B) with a flame ionization detector (FID) and a mass spectrometer (Agilent 5977A), illustrated in Fig. 1. Mixed softwood sawdust in the presence of a catalyst (1:10 ratio) was pyrolysed at $500{ }^{\circ} \mathrm{C}$ for $4 \mathrm{~s}$. A more detailed description of the analysis conditions is reported elsewhere [22].

Identification of the pyrolysis products was based upon their mass spectra and comparison of the mass spectra with the existing literature [23-26]. Calculations were performed by integrating the chromatographic peaks corresponding to identified compounds and normalizing the areas to the weight of the sample and to $100 \%$. The former approach was used to determine the yield while the latter gave the composition. 


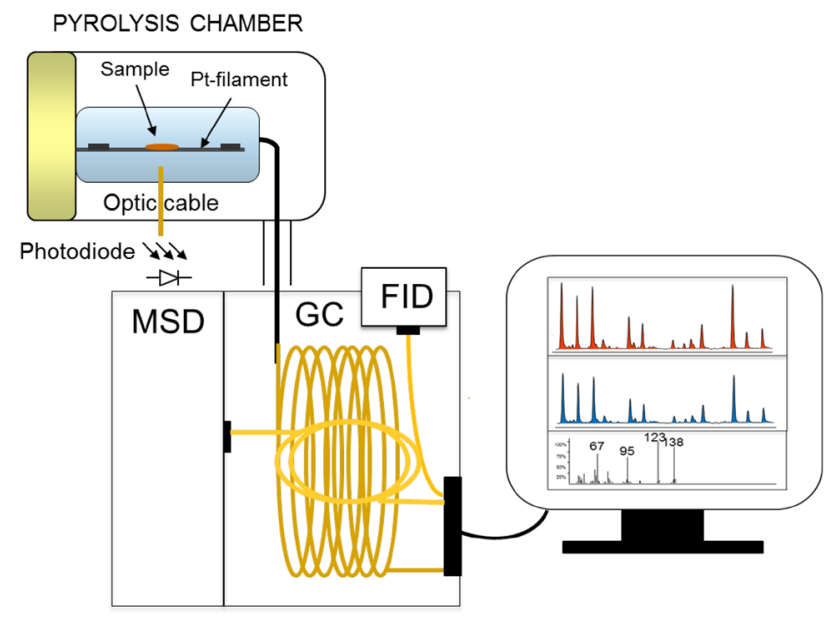

Fig. 1 Pyrolysis reactor set up: platinum filament type pyrolyzer combined with GC/MS

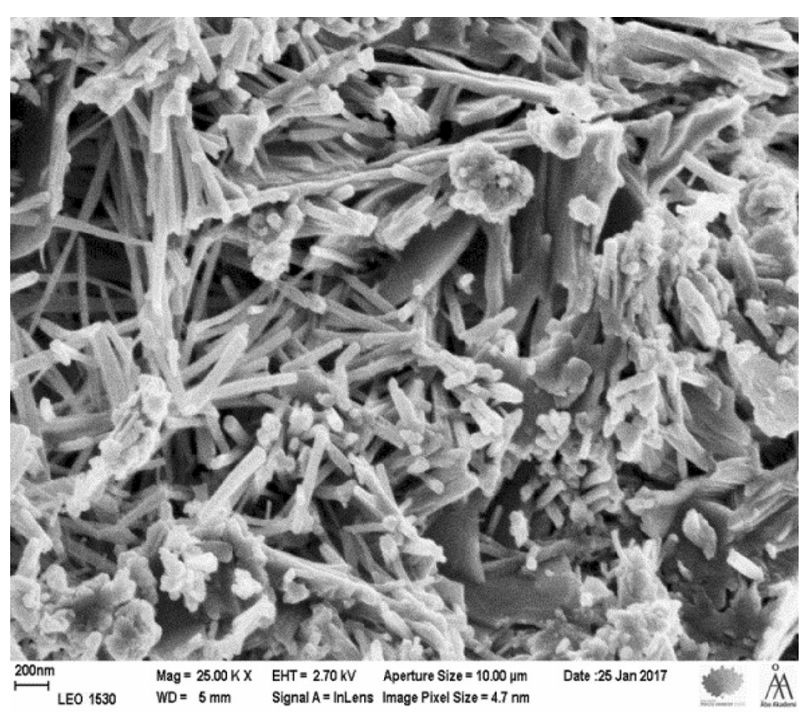

Fig. 2 SEM micrograph of industrial steel slag

\section{Results and Discussion}

\subsection{Catalysts Characterization Results}

\subsubsection{Scanning Electron Microscopy}

Electron micrographs of industrial slag and catalysts synthesized on its basis are presented in Figs. 2 and 3. Figure 2 displays SEM micrograph of the initial steel slag.

Figure 2 shows that the original industrial slag is represented by a combination of crystals with different shapes such as round shape crystals, needle shape crystals and also some amounts of platelets. Figure 3 displays SEM micrographs of the alkaline-treated materials prepared at varying such synthesis parameters as alkaline solution concentration [from $0.6 \mathrm{M}$ (a) to $2 \mathrm{M}$ (b); $4 \mathrm{~h}$ synthesis at ambient conditions], synthesis time [treatment by $0.6 \mathrm{M}$ solution for $48 \mathrm{~h} \mathrm{(c)]} \mathrm{and} \mathrm{temperature} \mathrm{[hydrothermal} \mathrm{syn-}$ thesis at $85^{\circ} \mathrm{C}$ with $\left.0.6 \mathrm{M} \mathrm{NaOH}(\mathrm{d})\right]$.

It can be concluded from Fig. 3 that the alkaline pretreatment has a significant effect on the crystals structure. The initial crystals were dissolved and new structures were formed upon treatment. Increasing the concentration of the alkaline solution from 0.6 to $2 \mathrm{M}$ results in formation of a mixture of crystal structures (Fig. 3b).

The variation of synthesis time promotes formation of faceted crystals of a clearly defined shape (Fig. 3c). It can be noted that with increasing synthesis time formation of larger crystals is facilitated. Moreover, needle shape crystals were formed between the large crystals.

Hydrothermal synthesis leads predominantly to formation of the round shape crystals (Fig. 3d), what is typically observed for hydrothermal treatment in basic media [27]. Moreover, an elevation in the synthesis temperature promotes formation of more clearly defined spherical structures with an increase of crystal sizes. Thereby, the crystal size is increased from $90 \mathrm{~nm}$ (for $65^{\circ} \mathrm{C}$ ) to $180 \mathrm{~nm}$ (treatment at $150{ }^{\circ} \mathrm{C}$ ).

Variation of the synthesis parameters has a significant effect on the structure of the formed crystals. Hydrothermal synthesis leads to formation of the round shape particles, which sizes increase upon treatment temperature elevation. An increase of the particle size is a result of acceleration of such processes as the nucleation and linear crystal growth [28]. Thus, a smaller crystal size is obtained at lower crystallization temperature due to a slower crystal growth rate. A similar process was observed by Johnson et al. [29] in hydrothermal synthesis of $\mathrm{NaX}$ zeolite from kaolin. The same trend was observed in the case of slag catalysts synthesis upon variation of the treatment time.

\subsubsection{Energy Disperse X-ray Analysis}

From the data obtained by the EDX analysis, it is clear that the original industrial slag has a high content of calcium (Table 2). In addition to aluminum, silicon and iron, such elements as sulfur, sodium, titanium and magnesium were found in the starting material.

The sulfur content was more than $3 \mathrm{wt} \%$. Clearly, such high concentration is undesirable as it can be a catalytic poison. Therefore, the sulfur content should be as low as possible.

Alkaline pretreatment using a $\mathrm{NaOH}$ solution resulted in a decrease in the content of $\mathrm{Na}$ (to $0.4 \mathrm{wt} \%$ ), $\mathrm{S}$ (to $1.3 \mathrm{wt} \%$ ), and $\mathrm{Ca}$ (to $24 \mathrm{wt} \%$ ). An increase in the synthesis time diminished sulfur (up to $0.7 \mathrm{wt} \%$ for $48 \mathrm{~h}$ synthesis), sodium (up 

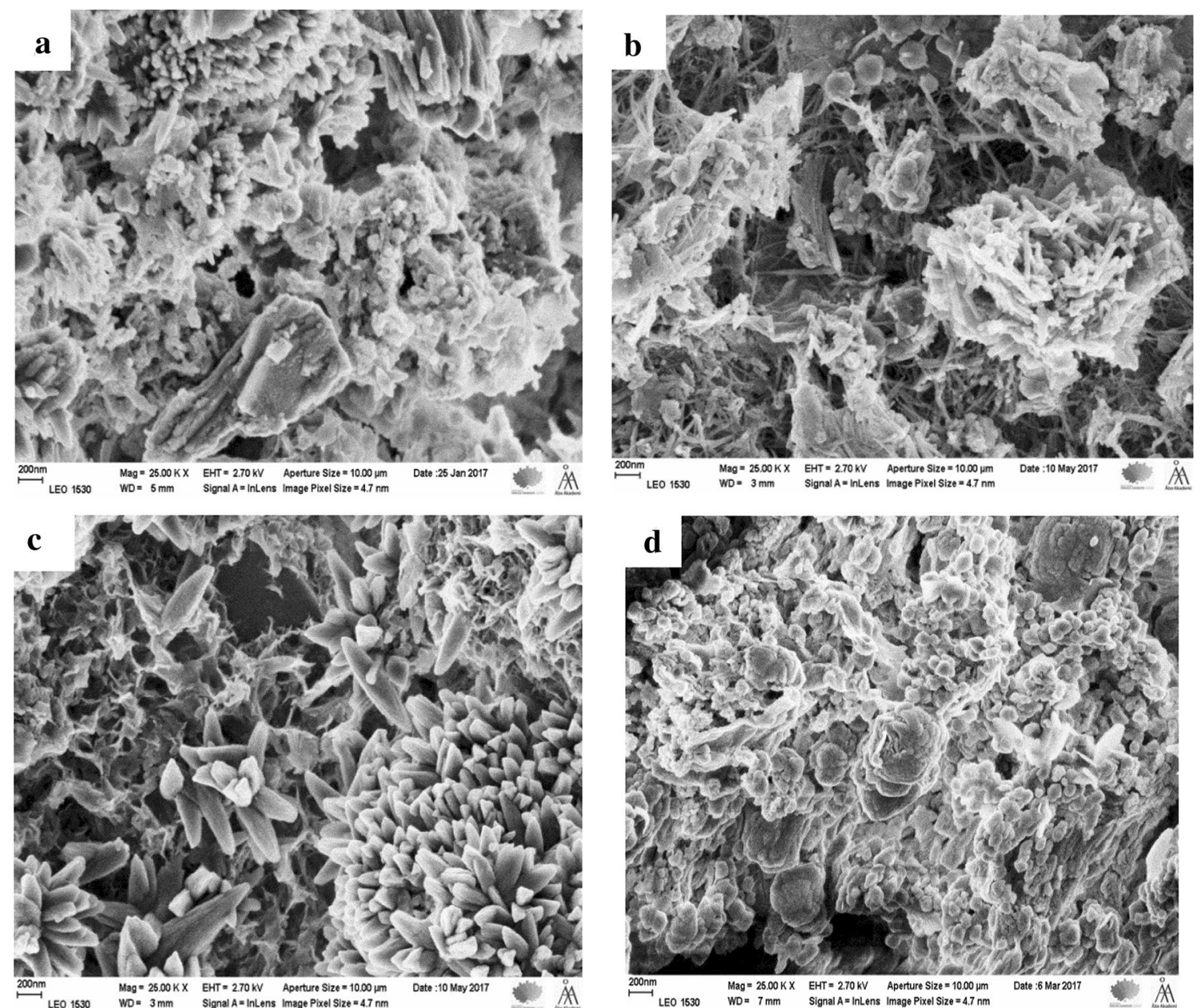

Fig. 3 SEM micrographs of synthesized materials varying synthesis conditions: a $0.6 \mathrm{M} \mathrm{NaOH}\left(4 \mathrm{~h}, 25{ }^{\circ} \mathrm{C}\right) ; \mathbf{b} 2 \mathrm{M} \mathrm{NaOH}\left(4 \mathrm{~h}, 25{ }^{\circ} \mathrm{C}\right)$; $\mathbf{c} 48 \mathrm{~h}$ $\left(0.6 \mathrm{M} \mathrm{NaOH}, 25{ }^{\circ} \mathrm{C}\right) ; \mathbf{d} 85^{\circ} \mathrm{C}(0.6 \mathrm{M} \mathrm{NaOH}, 4 \mathrm{~h})$

Table 2 Chemical compositions of slag used in this study (wt.\%)

\begin{tabular}{lllllllll}
\hline $\mathrm{O}$ & $\mathrm{Ca}$ & $\mathrm{Si}$ & $\mathrm{Fe}$ & $\mathrm{S}$ & $\mathrm{Na}$ & $\mathrm{Al}$ & $\mathrm{Ti}$ & $\mathrm{Mg}$ \\
\hline 49.91 & 34.67 & 3.89 & 4.78 & 3.37 & 1.62 & 0.73 & 0.68 & 0.35 \\
\hline
\end{tabular}

to $0.4 \mathrm{wt} \%$ for $48 \mathrm{~h}$ synthesis) and calcium content (up to $24 \%$ at $15 \mathrm{~h}$ synthesis). A further increase in the synthesis time ( $24 \mathrm{~h}$ and $48 \mathrm{~h}$ ) did not affect the calcium content in comparison with the original industrial slag.

A study of the synthesis temperature influence on the elemental composition of the samples showed a decrease in the content of $\mathrm{Na}$ up to $0.2 \mathrm{wt} \%$ (for synthesis at $85^{\circ} \mathrm{C}$ ), $\mathrm{S}$ up to $0.5 \mathrm{wt} \%$ (for synthesis at $150{ }^{\circ} \mathrm{C}$ ), and $\mathrm{Ca}$ up to $26 \mathrm{wt} \%$ (for pretreatments at $65^{\circ} \mathrm{C}$ and $85^{\circ} \mathrm{C}$ ).

\subsubsection{X-ray Powder Diffraction}

The structure and phase purity of the fresh industrial slag and materials synthesized on its basis were studied with
X-ray powder diffraction. XRD patterns are demonstrated in Fig. 4. The synthesized slag catalysts exhibit highly crystalline phases containing $\mathrm{CaCO}_{3}$ (rhombohedral, calcite), $\mathrm{Ca}(\mathrm{OH})_{2}$ (hexagonal, portlandite), $\mathrm{SiO}_{2}$ (hexagonal), $\mathrm{Al}_{3} \mathrm{O}_{3}$ (rhombohedral), $\mathrm{Fe}_{2} \mathrm{O}_{3}$ (rhombohedral) and $\mathrm{TiO}_{2}$ (tetragonal, rutile) [30, 31]. The diffraction patterns displayed changes of particular phases during different types of pretreatment. It is noteworthy, that the alkaline treatment upon variation of the synthesis parameters did not have an influence on the formation of new compounds in slag-based catalysts.

Figure 4a depicts the diffractograms of the fresh industrial slag and the catalysts synthesized by $4 \mathrm{~h}$ pretreatment with $\mathrm{NaOH}$ solutions of different molarity. It should be 

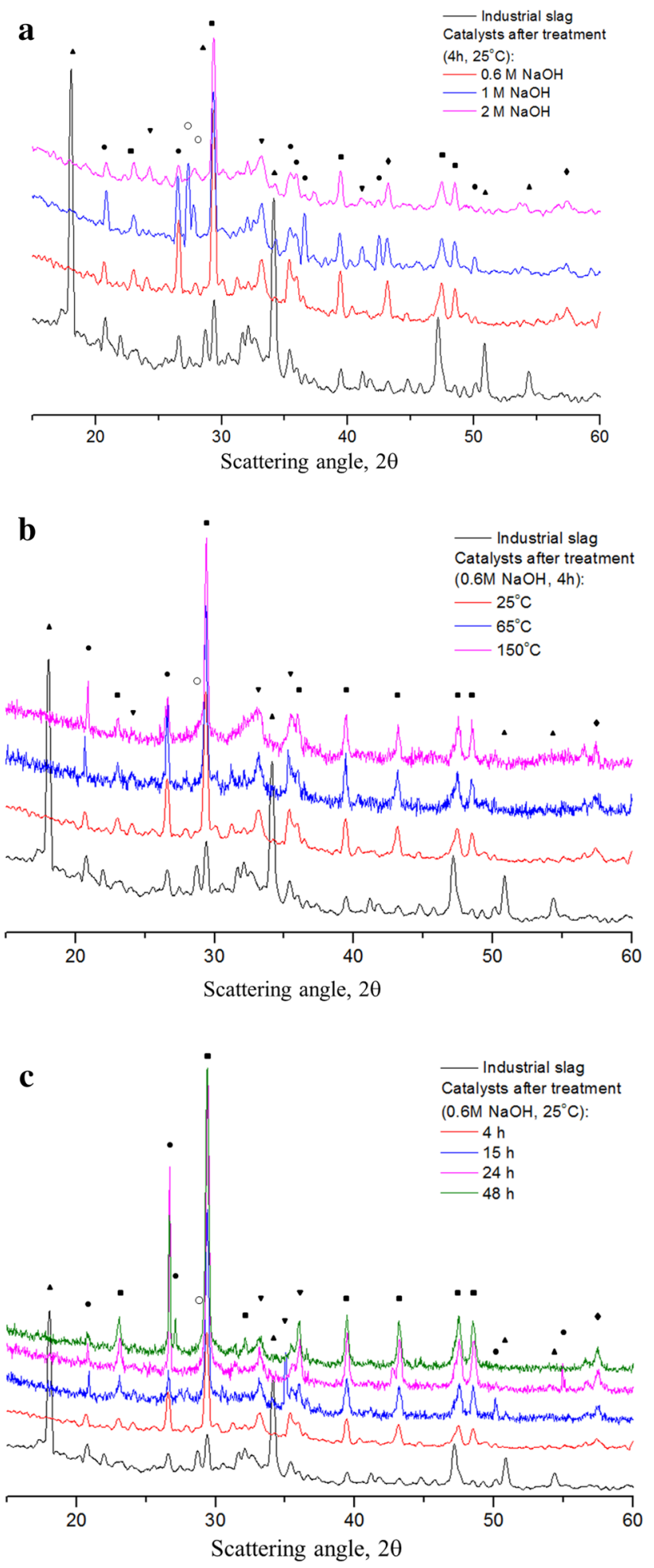

Fig. 4 XRD patterns of the samples pretreated by variation of: a the alkaline solution concentration; $\mathbf{b}$ the synthesis temperature and $\mathbf{c}$ time. [ $\mathrm{SiO}_{2}$ (filled circle); $\mathrm{Al}_{2} \mathrm{O}_{3}$ (filled diamond); $\mathrm{Fe}_{2} \mathrm{O}_{3}$ (inverted triangle); $\mathrm{TiO}_{2}$ (open circle); $\mathrm{Ca}(\mathrm{OH})_{2}$ (filled triangle); $\mathrm{CaCO}_{3}$ (filled square)] noted, that all types of alkaline pretreatment led to changes in XRD as compared with the patterns of the initial material.

For the non-treated industrial slag the preferred crystal orientation was related to the $\mathrm{Ca}(\mathrm{OH})_{2}$ phase (peaks at $2 \theta=18.1,34.1$ and $50.8^{\circ}$ ) with a relatively large crystal size. It can be seen from Fig. $4 \mathrm{a}$ that the starting material has a high content of calcium, which is consistent with the results of elemental analysis by EDX method.

The prepared samples are characterized by presence of an intense peak of $\mathrm{CaCO}_{3}\left(2 \theta=29.4^{\circ}\right)$. The peaks at $2 \theta=39.4^{\circ}$, $47.5^{\circ}$, and $48.5^{\circ}$, also belonging to this phase, did not shift during an increase of the alkaline solution concentration. The presence of $\mathrm{SiO}_{2}$ crystals $\left(2 \theta=20.7^{\circ}\right.$ and $\left.26.6^{\circ}\right)$ was also observed. The height of peaks related to this phase manifests creation of small crystallites. The peaks at $2 \theta 33.2^{\circ}$ and 35.5 correspond to $\mathrm{Fe}_{2} \mathrm{O}_{3}$ (rhombohedral) phase. It was found, that an alkaline solution concentration increase to $2 \mathrm{M}$ leads to a loss of crystalline $\mathrm{Fe}_{2} \mathrm{O}_{3}$ and transition to a weakly crystalline structure. The material synthesized using alkaline solution also contained $\mathrm{TiO}_{2}$ (polymorph rutile, $2 \theta=27.3^{\circ}$ and $27.7^{\circ}$ ).

Figure $4 \mathrm{~b}$ illustrates the diffractograms of the catalysts prepared by hydrothermal synthesis at $65^{\circ} \mathrm{C}$ and $150{ }^{\circ} \mathrm{C}$. Variation of the synthesis temperature affects the presence and amount of the phases in the slag-based catalysts. The intensity of the peaks is decreasing with elevation of the synthesis temperature, which indicates a decrease in the crystal sizes of observed phases and an increase in their crystallinity during hydrothermal synthesis. This phenomenon was also proved by SEM analysis. An exception is calcium carbonate $\left(2 \theta=29.3^{\circ}\right)$, which peak intensity increases for treated samples in comparison with the starting material. $\mathrm{Fe}_{2} \mathrm{O}_{3}$ peaks $\left(2 \theta=35.4^{\circ}\right)$ are wide and of low intensity. Such wide peaks are related to a small crystal size.

Figure $4 \mathrm{c}$ shows the diffractograms of the catalysts prepared upon variation of the synthesis time $(4,15,24$ and $48 \mathrm{~h}$ ). XRD patterns contain the same phases, that were present after treatment upon variation of the alkaline solution concentration and synthesis temperature: $\mathrm{CaCO}_{3}\left(2 \theta=23.1^{\circ}\right.$, $29.4^{\circ}, 31.4^{\circ}, 39.4^{\circ}, 43.1^{\circ}, 47.5^{\circ}$ and $\left.48.5^{\circ}\right), \mathrm{SiO}_{2}\left(2 \theta=20.9^{\circ}\right.$ and $\left.26.6^{\circ}\right)$ and $\mathrm{Fe}_{2} \mathrm{O}_{3}\left(2 \theta=33.2^{\circ}\right.$ and 35.6).

$\mathrm{XRD}$ analysis showed that the alkaline treatment upon variation of the synthesis parameters leads to formation of aggregates with a high degree of crystallinity and smaller sizes in comparison with the starting material.

\subsection{4 $\mathrm{N}_{2}$-Adsorption}

Synthesized slag catalysts exhibit type III isotherms (according to IUPAC classification [32]). This isotherm type is characteristic of nonporous solids and is typical for materials 
prepared using industrial slags [33]. However, a presence of the hysteresis loop indicates the presence of mesopores in alkaline-treated catalysts. The $\mathrm{N}_{2}$-physisorption data for the synthesized samples are shown in Table 3 .

It can be clearly seen that the alkaline pretreatment increased the surface area in all cases. Thereby, the highest surface area was achieved for the sample pretreated with $0.6 \mathrm{M} \mathrm{NaOH}$ solution (4-h synthesis at $25^{\circ} \mathrm{C}$ ). It should be noted that these treatment conditions resulted in the largest leaching of undesirable components as calcium and sulfur allowing at the same time to achieve the surface area 2.3 fold higher than of the initial industrial slag. A further increase of the alkaline solution concentration ( $1 \mathrm{M}$ and $2 \mathrm{M} \mathrm{NaOH})$ gave lower surface areas in comparison with $0.6 \mathrm{M} \mathrm{NaOH}$. Hydrothermal synthesis at $65^{\circ} \mathrm{C}$ (pretreatment with $0.6 \mathrm{M}$ $\mathrm{NaOH}$ during $4 \mathrm{~h}$ ) allowed a relatively high value of the surface area $\left(40 \mathrm{~m}^{2} / \mathrm{g}\right)$. These changes can be related to agglomeration of the formed crystals indicated by SEM (Fig. 3). Elevation of the synthesis time from 8 to $48 \mathrm{~h}$ (pretreatment with $0.6 \mathrm{M} \mathrm{NaOH}$ at ambient conditions) gave initially an increase of the surface area reaching a maximum value of $41 \mathrm{~m}^{2} / \mathrm{g}$ for 15 -h synthesis.

It should be noted that micro- and mesopore volumes of the synthesized catalysts increased in comparison with the initial material in all cases. When the alkaline solution concentration was changed, the maximum pore volume was obtained for $1 \mathrm{M} \mathrm{NaOH}\left(4 \mathrm{~h}\right.$ synthesis at $25^{\circ} \mathrm{C}$ ). Hydrothermal synthesis did not have a strong influence on the pores formation. In fact, an increase of the synthesis temperature diminished the mesopore volume. Elevation of the synthesis

Table 3 Values of the specific surface area, micropore and mesopore volumes of industrial slag and catalysts synthesized on its basis

\begin{tabular}{llll}
\hline Catalyst & $\begin{array}{l}\text { Specific } \\
\text { surface area, } \\
\mathrm{m}^{2} / \mathrm{g}\end{array}$ & $\begin{array}{l}\text { Micropore } \\
\text { volume, } \\
\mathrm{cm}^{3} / \mathrm{g}\end{array}$ & $\begin{array}{l}\text { Mesopore } \\
\text { volume, } \\
\mathrm{cm}^{3} / \mathrm{g}\end{array}$ \\
\hline $\begin{array}{l}\text { Non-treated material } \\
\text { Industrial slag }\end{array}$ & 19 & 0.0069 & 0.0598 \\
Effect of alkaline solution concentration \\
$\begin{array}{l}\text { 0.6 M NaOH solution } \\
\text { 1 M NaOH solution }\end{array}$ & 44 & 0.0156 & 0.0992 \\
2 M NaOH solution & 36 & 0.0130 & 0.1123 \\
Hydrothermal synthesis & 0.0129 & 0.0895 \\
Synthesis at $65{ }^{\circ} \mathrm{C}$ & 40 & & \\
Synthesis at $85{ }^{\circ} \mathrm{C}$ & 28 & 0.0142 & 0.0769 \\
Synthesis at $150{ }^{\circ} \mathrm{C}$ & 24 & 0.0099 & 0.0589 \\
Influence of synthesis time & 0.0085 & 0.0425 \\
8-h synthesis & 35 & & \\
15-h synthesis & 41 & 0.0123 & 0.0769 \\
24-h synthesis & 37 & 0.0147 & 0.0802 \\
48-h synthesis & 38 & 0.0132 & 0.0889 \\
\hline
\end{tabular}

time to $24 \mathrm{~h}$ gave an increase in mesopores, however a further increase in time had no significant effect.

A larger porosity of the synthesized catalysts can be related to two main processes taking place during the alkaline treatment. The first one is leaching of the components (mostly Ca) from the raw material confirmed by the elemental analysis. Transformations of the crystal structure are another important phenomenon influencing creation of the pore structure. According to SEM (Fig. 3) each treatment type has a specific influence on the crystal formation, which also has an impact on the surface area. Therefore, a higher alkaline solution concentration results in lower degree of crystallinity observed by XRD. An increase of the hydrothermal synthesis temperature led to formation of large crystals (with an average size of $220 \mathrm{~nm}$ ) partially sintered (Fig. 3d). In both cases these processes resulted in pore blocking and a decline of the surface area. An increase of the synthesis time promotes formation of clearly defined crystallites indicated by SEM (Fig. 3c) with creation of a well-developed porous structure.

\subsubsection{Transmission Electron Microscopy}

Transmission electron microscopy characterization was applied to study the structure, porosity, metal particle size and channel systems in the initial industrial slag and after several different kinds of pretreatment. Figure 5 illustrates the internal structure of synthesized slag-based catalysts, which consists of internal channels and pores.

The porous structure of the material is clearly visible in Fig. 5b. The structure of the original industrial slag comprises external pores and channels in the internal part of the particle. An average pore diameter was determined to be $18 \mathrm{~nm}$. Similar to the original material, the sample after pretreatment with $0.6 \mathrm{M} \mathrm{NaOH}$ contains pores with the average pore diameter of $6.6 \mathrm{~nm}$ on the external surface and has also internal channels. Formation of pores and channels during the alkaline treatment is explained by selective leaching of some elements from the initial industrial slag. This phenomenon leads to changes in the surface area and creation of mesoporosity.

Formation of well-defined crystals with the presence of pores on the external surface and internal channel systems was observed for catalysts prepared under synthesis time and temperature variations.

Figure 6 illustrates TEM micrograph of a slag-based catalyst prepared by $24-\mathrm{h}$ pretreatment with $0.6 \mathrm{M} \mathrm{NaOH}$ solution.

Formation of metal/metal oxide nanoparticles with the average diameter of $7.5 \mathrm{~nm}$ and the predominant size of $8 \mathrm{~nm}$ can be clearly seen from Fig. 6 . 

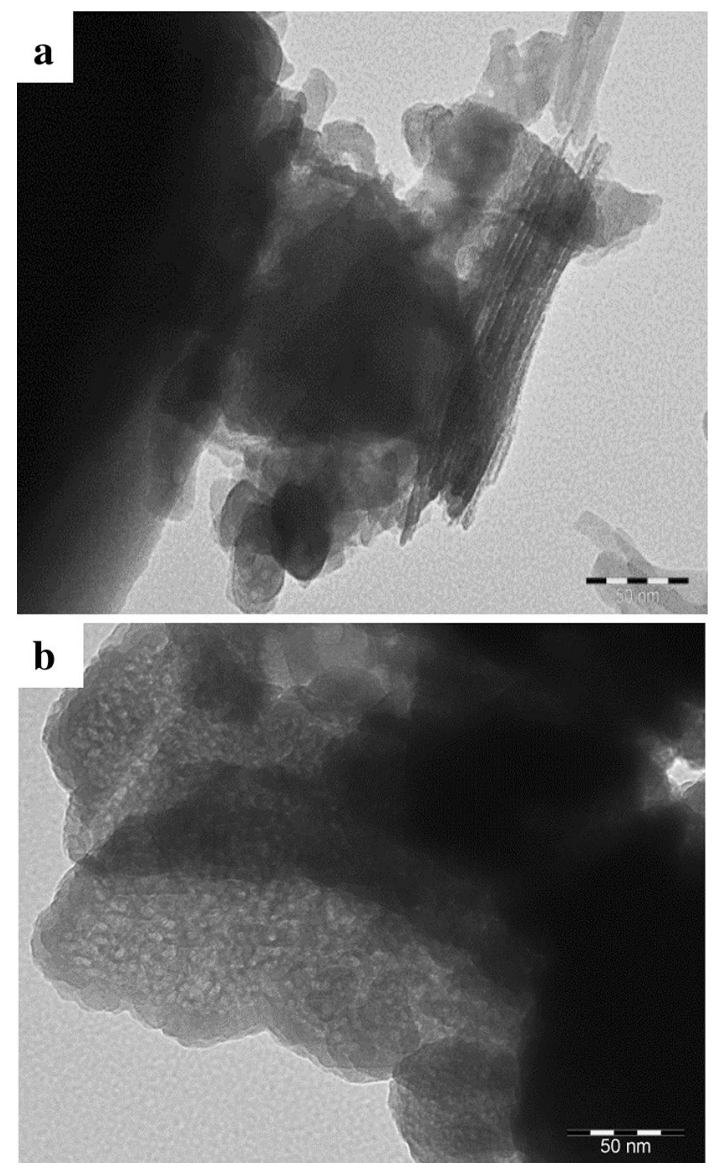

Fig. 5 TEM micrographs of the internal structure of synthesized materials: a internal channels; $\mathbf{b}$ pores on the external surface

\subsubsection{Temperature Programmed Desorption}

Temperature programmed desorption of $\mathrm{NH}_{3}$ and $\mathrm{CO}_{2}$ was performed for investigation of the properties of synthesized catalysts such as the presence, amount and strength of the acid and basic sites, respectively.
The presence of acid sites in this type of materials can be explained by the presence of sulfur, silica and alumina phases. Figure 7 demonstrates TPD- $\mathrm{NH}_{3}$ curves of the original material and the slag-based catalysts upon variation of the synthesis parameters.

From the obtained data it can be inferred that the catalytic samples have all types of acid sites - weak ( $<770 \mathrm{~K})$, medium (770-1020 K) and strong (>1020 K). Similar temperature ranges were observed for catalysts synthesized from gasified straw slag [34]. It is also clearly seen that there were no considerable shifts of the curves during variation of synthesis parameters (Fig. 7).

Basic properties of slag materials are directly related to the elemental composition, namely presence and quantity of the main components- $\mathrm{CaCO}_{3} / \mathrm{Ca}(\mathrm{OH})_{2}, \mathrm{MgO}, \mathrm{Na}_{2} \mathrm{O}$ and $\mathrm{Fe}_{2} \mathrm{O}_{3}$.

Figure 8 illustrates TPD- $\mathrm{CO}_{2}$ curves of the starting slag and the slag-based materials treated with $0.6 \mathrm{M} \mathrm{NaOH}$ upon variation of the synthesis parameters.

Analysis of the obtained results confirmed by EDX showed that the original and treated materials are basic containing only strong sites ( $>750 \mathrm{~K}$ ).

Quantitative characterization of the acid sites $(\mu \mathrm{mol} / \mathrm{g})$, namely the amount and distribution of weak, medium and strong sites, is presented in Table 4.

Concentration of the acid sites lower than in the original slag is characteristic of all types of synthesis (Table 4). A decrease in the amount of acid sites is a consequence of leaching of elements with acidic properties during alkaline pretreatment. All synthesized catalysts exhibited only one high and broad $\mathrm{NH}_{3}$ desorption peak in the region of $770-1020 \mathrm{~K}$ indicating that the acid sites of the catalytic samples are of medium strength (Fig. 7). It can be seen from Table 4 that an increase of the alkali solution concentration from 0.6 to $2 \mathrm{M}$ leads to an increase in the total acidity up to $42 \mu \mathrm{mol} / \mathrm{g}$. The results obtained upon variation of the synthesis parameters directly depend on the changes in the elemental composition of catalytic materials. Thereby,
Fig. 6 TEM micrograph of the industrial slag after 24 -h pretreatment and the corresponding particle size distribution

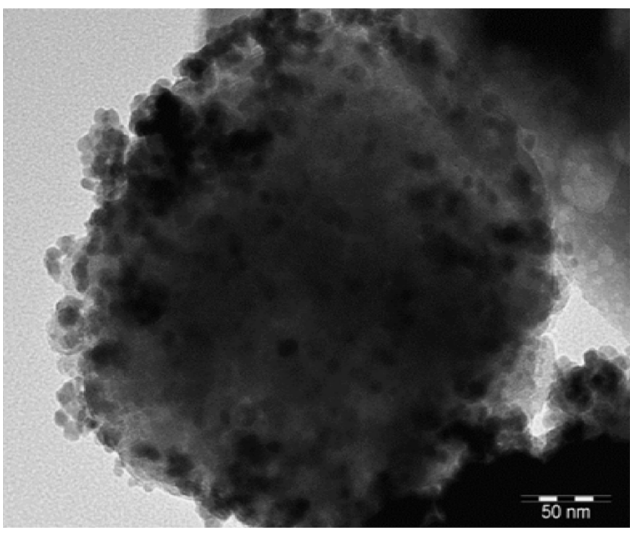



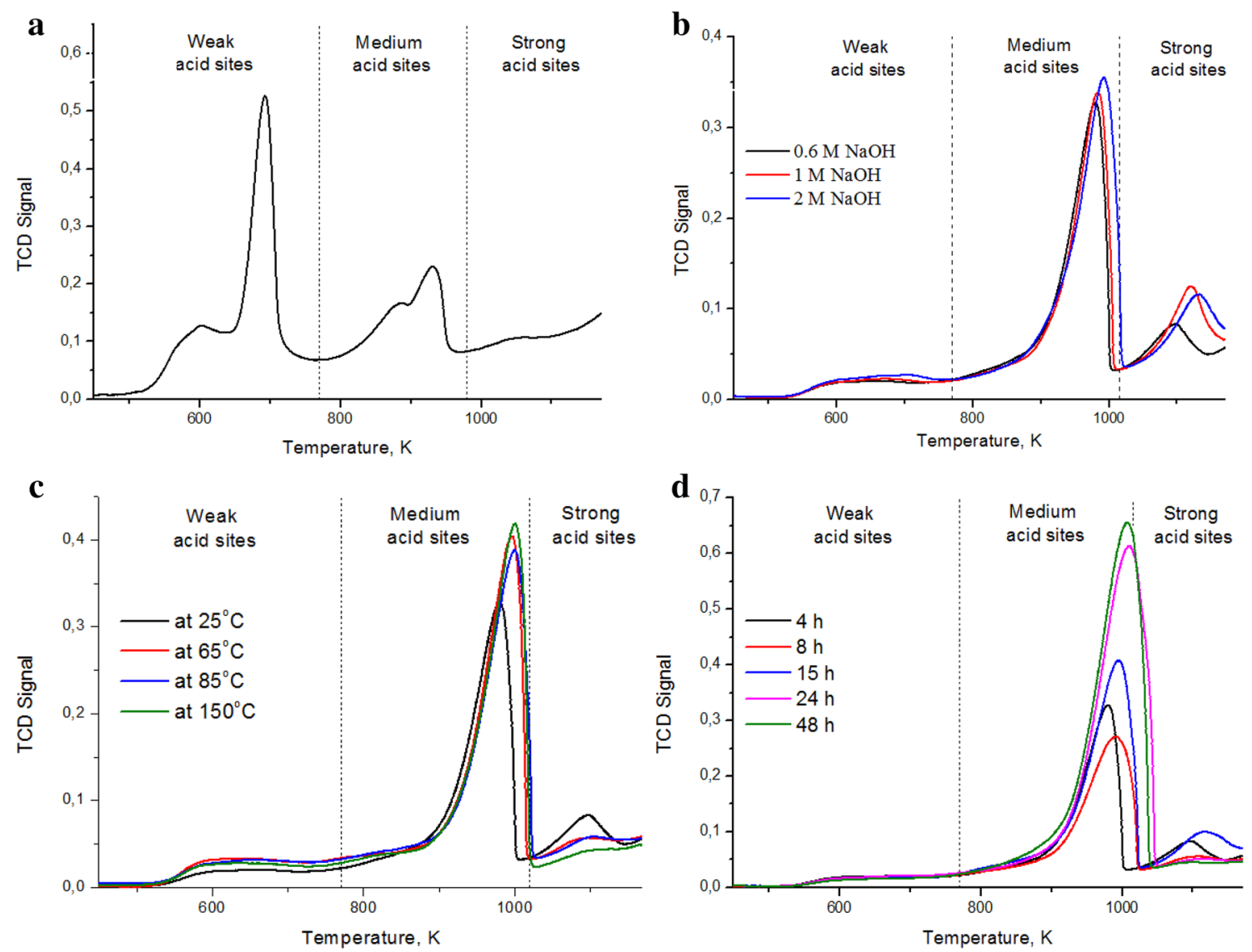

Fig. 7 TPD- $\mathrm{NH}_{3}$ spectra of a industrial slag and samples synthesized on its basis upon variation synthesis parameters: b alkaline solution concentration; $\mathbf{c}$ synthesis temperature; $\mathbf{d}$ synthesis time

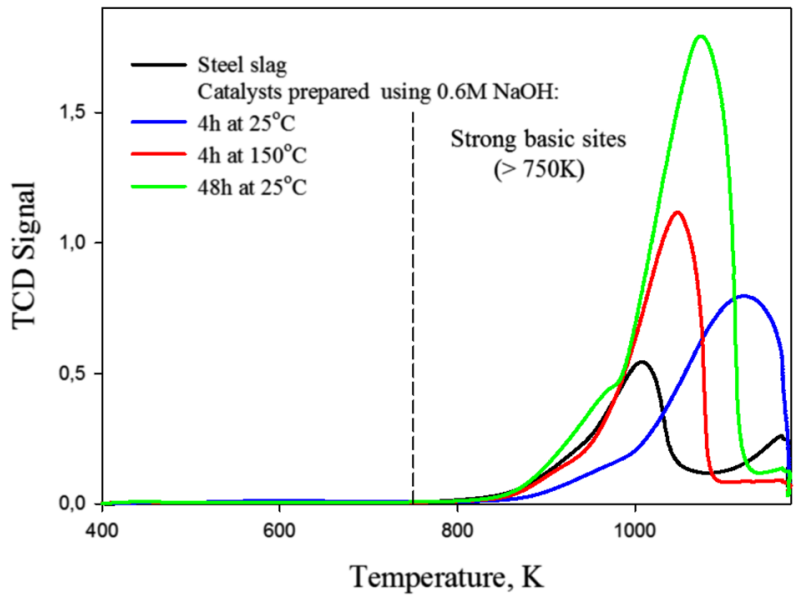

Fig. 8 TPD- $\mathrm{CO}_{2}$ spectra of industrial slag and samples synthesized on its basis

an increase of the treating agent concentration results in a higher content of acidic compounds, which in turn leads to an increase in the total acidity of the materials. Variation of the hydrothermal synthesis temperature did not significantly influence acidity of the synthesized materials. An increase of the synthesis time from 8 to $48 \mathrm{~h}$ resulted in an increase of the acid sites amount up to $58 \mu \mathrm{mol} / \mathrm{g}$ (for $48 \mathrm{~h}$ synthesis).

From analysis of TPD- $\mathrm{CO}_{2}$ results (Table 4) it can be clearly seen that the alkaline treatment using $0.6 \mathrm{M} \mathrm{NaOH}$ solution allows 1.5 fold increase in the number of the basic sites compared to the original material. However, a further increase of the alkaline solution concentration to $2 \mathrm{M}$ gave a decrease of the active sites $(14 \mu \mathrm{mol} / \mathrm{g})$ as a result of losses in the degree of crystallinity. The highest basicity for the materials synthesized by the hydrothermal treatment is $50 \mu \mathrm{mol} / \mathrm{g}$ (for synthesis performed at $150{ }^{\circ} \mathrm{C}$ ).

The maximum basicity of slag-based catalysts was achieved upon an increase of the synthesis time from 8 to $48 \mathrm{~h}$ being equal to $92 \mu \mathrm{mol} / \mathrm{g}$. This catalyst characterized by high degree of crystallinity of formed phases indicated by XRD, well-defined crystal shape and relatively high surface area.

It was found that the amount of active sites has a direct correspondence to the specific surface area [35]. An increase of the surface area and porosity in materials leads to appearance of a larger number of surface active sites, which in 
Table 4 Acidity and basicity of the catalysts synthesized from the industrial slag

\begin{tabular}{|c|c|c|c|c|c|}
\hline \multirow[t]{2}{*}{ Material } & \multicolumn{3}{|c|}{ Acid sites, $\mu \mathrm{mol} / \mathrm{g}$} & \multirow{2}{*}{$\begin{array}{l}\text { Total acidity, } \\
\mu \mathrm{mol} / \mathrm{g}\end{array}$} & \multirow{2}{*}{$\begin{array}{l}\text { Total basic- } \\
\text { ity, } \mu \mathrm{mol} / \mathrm{g}\end{array}$} \\
\hline & $\begin{array}{l}\text { Weak } \\
(<770 \mathrm{~K})\end{array}$ & $\begin{array}{l}\text { Medium } \\
(770-1020 \mathrm{~K})\end{array}$ & $\begin{array}{l}\text { Strong } \\
(>1020 \mathrm{~K})\end{array}$ & & \\
\hline \multicolumn{6}{|l|}{ Non-treated material } \\
\hline Industrial slag & 38 & 25 & 14 & 77 & 33 \\
\hline \multicolumn{6}{|c|}{ Effect of alkaline solution concentration } \\
\hline $0.6 \mathrm{M} \mathrm{NaOH}$ solution & 3 & 24 & 7 & 34 & 51 \\
\hline $1 \mathrm{M} \mathrm{NaOH}$ solution & 4 & 23 & 10 & 37 & 31 \\
\hline $2 \mathrm{M} \mathrm{NaOH}$ solution & 5 & 27 & 10 & 42 & 14 \\
\hline \multicolumn{6}{|l|}{ Hydrothermal synthesis } \\
\hline Synthesis at $65^{\circ} \mathrm{C}$ & 6 & 29 & 5 & 40 & 19 \\
\hline Synthesis at $85^{\circ} \mathrm{C}$ & 5 & 30 & 6 & 41 & 35 \\
\hline Synthesis at $150^{\circ} \mathrm{C}$ & 5 & 29 & 4 & 38 & 50 \\
\hline \multicolumn{6}{|c|}{ Influence of synthesis time } \\
\hline 8-h synthesis & 3 & 24 & 5 & 32 & 24 \\
\hline 15 -h synthesis & 3 & 32 & 9 & 44 & 32 \\
\hline 24-h synthesis & 3 & 51 & 5 & 59 & 57 \\
\hline 48-h synthesis & 3 & 51 & 4 & 58 & 92 \\
\hline
\end{tabular}

turn can lead to higher catalytic activity. However, for such systems as slag catalysts catalytic behavior is complicated by the presence of several oxides and differences in the formed crystals.

\subsection{Catalysts Testing}

Analytical pyrolysis is an effective method of biomass decomposition giving bio oil as the desired product [36, 37]. The use of synthesized catalysts in the current work changed the product distribution in catalytic fast pyrolysis in comparison with the thermal pyrolysis and a non-modified industrial slag. However, there were no additional compounds identified in catalytic pyrolysis in comparison to the non-catalytic one indicating similar cracking pathways.

The degradation products were grouped as $\mathrm{CO}_{2}$, aldehydes, furans, pyrans, anhydrosugars, p-hydroxyphenyl and guaiacyl. A list of the identified and integrated compounds is presented in Table 5.

The obtained degradation products contained besides $\mathrm{CO}_{2}$ also other compounds (i.e., acetic acid, acetaldehyde, guaiacol, vanillin, eugenol, phenol) typical for pyrolysis of softwood biomass [38, 39]. Changes in the product distribution using different alkaline concentrations, synthesis temperature and time are shown in Fig. 9. All synthesized catalysts increased conversion of carbohydrates to low molecular hydrocarbons. This was seen as an increase in the relative amounts of $\mathrm{CO}_{2}$, furans, ketones, alcohols and acids.

Catalytic pyrolysis altered to a lesser extent the lignin structure. A minor enrichment of the lignin degradation products was observed together with an increase in $p$-hydroxyphenyl type of lignin degradation products. This indicated demethylation activity of the synthesized catalysts on lignin guaiacyl type units.

Catalytic activity of the obtained slag-based materials showed a strong dependence on the synthesis parameters, what can be seen from not only the distribution, but also the yield of degradation products (Fig. 10).

In the case of catalytic pyrolysis a lower amount of the liquid pyrolysis products can be related to a higher catalytic activity resulting in enhanced char and gas formation. In most cases, utilization of the slag-based catalysts decreases the bio-oil yield. The highest activity was achieved for the catalyst exhibiting the maximum surface area and mesopore volume and allowing a more efficient access of the reactants to the active sites.

The yield was increased at elevated synthesis temperature and especially synthesis time. The highest liquid product yield was, in particular, obtained for the material when the synthesis time was $48 \mathrm{~h}$, allowing the highest amount of both basic and acid sites in the catalyst.

\section{Conclusions}

In the present study, synthesis of the slag-based catalysts was performed by alkaline pretreatment of an industrial steel slag with $\mathrm{NaOH}$ solution by varying such synthesis parameters as the alkaline solution concentration, synthesis temperature and time.

XRD analysis showed that the industrial slag and the catalysts synthesized on its basis exhibit highly crystalline 
Table 5 Compounds that were identified and calculated from the catalytic pyrolysis experiments

\begin{tabular}{|c|c|}
\hline Gas & Anhydrosugars \\
\hline $\mathrm{CO}_{2}$ & 1,4-Anhydroxylopyranose \\
\hline Alcohols & 1,5-Anhydroarabinofuranose \\
\hline Methanol & 1,6-Anhydromannopyranose \\
\hline Acids & 1,6-Anhydroglucopyranose \\
\hline Acetic acid & $p$-Hydroxyphenyl type degradation products \\
\hline Aldehydes & Phenol \\
\hline Formaldehyde & 2-Methylphenol \\
\hline Acetaldehyde & 4-Methylphenol \\
\hline Propenal & Guaiacyl type degradation products \\
\hline 3-Hydoxypropanal & Guaiacol \\
\hline Butanedial & 3-Methylguaiacol \\
\hline Hydroxyacetaldehyde & 4-Methylguaiacol \\
\hline 3-Butenal-2-one & 4-Ethylguaiacol \\
\hline Ketones (+ester) & 4-Propylguaiacol \\
\hline Propanal-2-one & 4-Vinylguaiacol \\
\hline Methyl-2-oxopropanoate & Eugenol \\
\hline 4-Cyclopenten-1,3-dione & cis-Isoeugenol \\
\hline Furans & trans-Isoeugenol \\
\hline$(3 H)$-Furan-2-one & Guaiacylpropyne \\
\hline$(2 H)$-Furan-3-one & Guaiacylallene \\
\hline 3-Furaldehyde & Vanillin \\
\hline 2-Furaldehyde & Homovanillin \\
\hline 3-Furfyl alcohol & Acetoguaiacone \\
\hline 5-Methyl-2-furaldehyde & Guaiacylacetone \\
\hline (5H)-Furan-3-one & 4-(Oxy-allyl)guaiacol \\
\hline Methyl-dihydro-(2H)-pyran-2-one & 4-(1-Hydroxy-prop-2-enyl)guaiacol \\
\hline Pyrans & Dihydroconiferyl alcohol \\
\hline 1,5-Anhydro-4-deoxypent-1-en-3-ulose & cis-Coniferyl alcohol \\
\hline 5-Hydroxymethyl-2-tetrahydrofuraldehyde-3-one & trans-Coniferyl alcohol \\
\hline 5-Hydroxymethyl-2-furaldehyde & Coniferaldehyde \\
\hline 1,4-Dideoxy-D-glycero-hex-1-enopyranos-3-ulose & \\
\hline
\end{tabular}

phases containing $\mathrm{CaCO}_{3}, \mathrm{Ca}(\mathrm{OH})_{2}, \mathrm{SiO}_{2}, \mathrm{Al}_{2} \mathrm{O}_{3}, \mathrm{Fe}_{2} \mathrm{O}_{3}$ and $\mathrm{TiO}_{2}$. It was found that an increase in the alkaline solution concentration leads to a loss of crystalline $\mathrm{Fe}_{2} \mathrm{O}_{3}$ and transition to a weakly crystalline structure, which explains a decrease of the surface area. Alkaline pretreatment of the industrial slag allows an increase of the surface area exceeding almost twofold the surface area of the parent material. The maximum value was achieved for $4 \mathrm{~h}$ pretreatment with $0.6 \mathrm{M} \mathrm{NaOH}$ being equal to $44 \mathrm{~m}^{2} / \mathrm{g}$. An increase in the surface area was accompanied with formation of a porous structure including pores on the external surface and internal channels as determined by TEM. Formation of metal/metal oxides nanoparticles with an average diameter of $7.5 \mathrm{~nm}$ was also observed. TPD showed that the original and treated materials exhibited strong basicity due to presence of large amounts of basic oxides.

Fast catalytic pyrolysis of softwood sawdust demonstrated that the slag catalysts changed the product distribution and the yield of the degradation products in comparison with thermal pyrolysis or application of an unmodified industrial slag. The highest liquid yield was achieved for the catalyst exhibiting the highest amount of both acid and basic sites (48-h treated slag with $0.6 \mathrm{M} \mathrm{NaOH}$ at ambient conditions). 
Fig. 9 Distribution of degradation products formed in fast pyrolysis of softwood sawdust
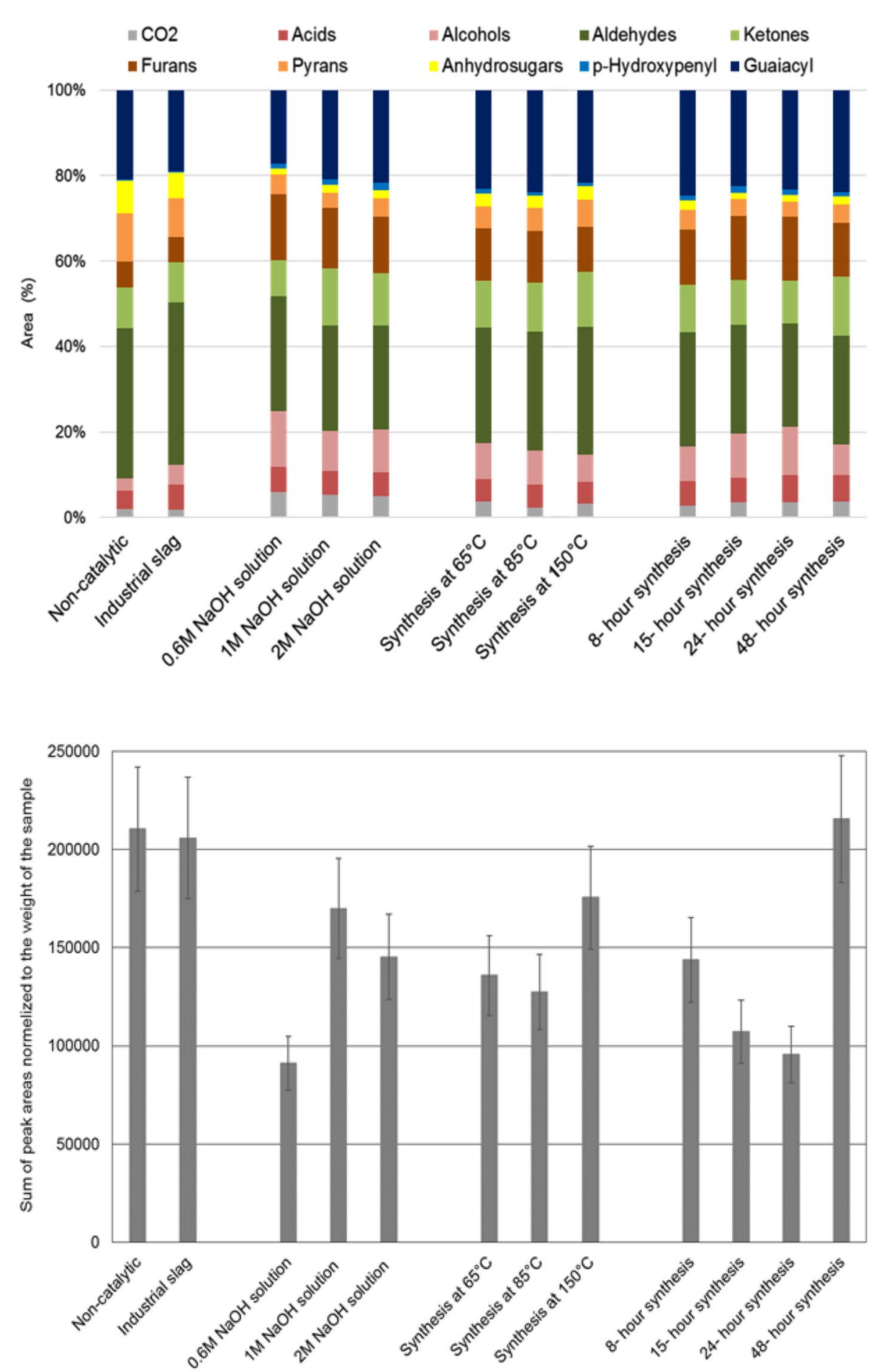

Fig. 10 The yield of the degradation products
Acknowledgements Open access funding provided by Abo Akademi University (ABO). This work is part of the activities at the Abo Akademi University Process Chemistry Centre and VTT Technical Research Centre of Finland Ltd. The Finnish Funding Agency for Innovation (Tekes) is acknowledged for funding via the Green Growth program.

Open Access This article is distributed under the terms of the Creative Commons Attribution 4.0 International License (http://creativeco mmons.org/licenses/by/4.0/), which permits unrestricted use, distribution, and reproduction in any medium, provided you give appropriate credit to the original author(s) and the source, provide a link to the Creative Commons license, and indicate if changes were made. 


\section{References}

1. Dhoble YN, Ahmed S (2018) Review on the innovative uses of steel slag for waste minimization. J Mater Cycles Waste Manag 20:1373-1382

2. Piatak NM, Parsons MB, Seal RR II (2015) Characteristics and environmental aspects of slag: a review. Appl Geochem 57:236-266

3. Yildirim IZ, Prezzi M (2011) Chemical, mineralogical and morphological properties of steel slag. Adv Civil Eng 2011:1-13

4. Veselská V, Majzlan J (2016) Environmental impact and potential utilization of historical $\mathrm{Cu}-\mathrm{Fe}-\mathrm{Co}$ slags. Environ Sci Pollut Res 23:7308-7323

5. EUROSLAG, Products properties. https://www.euroslag.com/ products/properties/

6. Ulubeylia GC, Artir R (2015) Sustainability for blast furnace slag: use of some construction wastes. Procedia Soc Behav Sci 195:2191-2198

7. Ilyushechkin AY, Roberts DG, French D, Harris DJ (2012) IGCC solids disposal and utilisation. CSIRO, Canberra

8. Bocci E (2018) Use of ladle furnace slag as filler in hot asphalt mixtures. Constr Build Mater 161:156-164

9. Balczar I, Korim T, Hullar H, Boros A, Mako E (2017) Manufacture of air-cooled slag-based alkali-activated cements using mechanochemical activation. Constr Build Mater 137:216-223

10. Kumar S, Kumar R, Bandopadhyay A, Alex TC, Ravi Kumar B, Das SK, Mehrotra SP (2008) Mechanical activation of granulated blast furnace slag and its effect on the properties and structure of portland slag cement. Cem Concr Compos 30:679-685

11. Liu J, Yu Q, Zuo Z, Yang F, Duan W, Qin Q (2017) Blast furnace slag obtained from dry granulation method as a component in slag cement. Constr Build Mater 131:381-387

12. Lee NK, Kim HK, Park IS, Lee HK (2013) Alkali-activated, cementless, controlled low-strength materials (CLSM) utilizing industrial by-products. Constr Build Mater 49:738-746

13. Duan W, Yu Q, Liu J, Hou L, Xie H, Wang K, Qin Q (2016) Characterizations of the hot blast furnace slag on coal gasification reaction. Appl Therm Eng 98:936-943

14. Dimitrova S, Ivanov G, Mehandjiev D (2004) Metallurgical slag as a support of catalysts for complete oxidation in the presence of ozone. App Catal A Gen 266:81-87

15. Yu H, Ma T, Shen Y, Chen D (2017) Experimental study on catalytic effect of biomass pyrolysis volatile over nickel catalyst supported by waste iron slag. Int J Eng Res 41:2063-2073

16. Kar Y, Gürbüz Z (2016) Application of blast furnace slag as a catalyst for catalytic cracking of used frying sunflower oil. Energy Expl Exploit 34:262-272

17. Okoye PU, Abdullah AZ, Hameed BH (2017) Stabilized ladle furnace steel slag for glycerol carbonate synthesis via glycerol transesterification reaction with dimethyl carbonate. Energy Convers Manag 133:477-485

18. Dessau RM, Valyocsik EW, Goeke NH (1992) Aluminum zoning in ZSM-5 as revealed by selective silica removal. Zeolites 12:776-779

19. Ogura M, Shinomiya S, Tateno J, Nara Y, Kikuchi E, Matsukata M (2000) Formation of uniform mesopores in ZSM-5 zeolite through treatment in alkaline solution. Chem Lett 29:882-883

20. Huang S, Chen P, Yan B, Wang S, Shen Y, Ma X (2013) Modification of $Y$ zeolite with alkaline treatment: textural properties and catalytic activity for diethyl carbonate synthesis. Ind Eng Chem Res 52:6349-6356

21. Liu J, Cui L, Wang L, Ni X, Zhang S, Jin Y (2014) Alkaline-acid treated mordenite and beta zeolites featuring mesoporous dimensional uniformity. Mater Lett 132:78-81
22. Wikberg H, Ohra-aho T, Honkanen M, Kanerva H, Harlin A, Vippola M, Laine C (2016) Hydrothermal carbonization of pulp mill streams. Bioresour Technol 212:236-244

23. Faix O, Fortmann I, Bremer J, Meier D (1991) Thermal degradation products of wood: a collection of electron-impact (EI) mass spectra of polysaccharide derived products. Holz Roh Werkst 49:299-304

24. Faix O, Fortmann I, Bremer J, Meier D (1991) Thermal degradation products of wood: gas chromatographic separation and mass spectrometric characterization of polysaccharide derived products. Holz Roh Werkst 49:213-219

25. Faix O, Meier D, Fortmann I (1990) Thermal degradation products of wood: gas chromatographic separation and mass spectrometric characterization of monomeric lignin derived products. Holz Roh Werkst 48:281-285

26. Faix O, Meier D, Fortmann I (1990) Thermal degradation products of wood: a collection of electron-impact (EI) mass spectra of monomeric lignin derived products. Holz Roh Werkst 48:351-354

27. Kuwahara Y, Ohmichi T, Kamegawa T, Moria K, Yamashita $\mathrm{H}$ (2010) A novel conversion process for waste slag: synthesis of a hydrotalcite-like compound and zeolite from blast furnace slag and evaluation of adsorption capacities. J Mater Chem 20:5052-5062

28. Molina A, Poole C (2004) A comparative study using two methods to produce zeolites from fly ash. Miner Eng 17:167-173

29. Johnson EBG, Asik J, Arshad SE (2016) The effect of crystallization time and temperature on hydrothermal synthesis of zeolite naxfrom bongawan kaolin. FEIIC Int J Eng Technol 13:33-39

30. Inorganic Crystal Structure Database (ICSD), version 2.1.0 (2012) Fiz Karlsruhe. http://www2.fiz-karlsruhe.de/icsd_home.html

31. Powder Diffraction File 2 (PDF-2), International Centre for Diffraction Data (ICDD), 1996, 1-46

32. IUPAC (1984) Reporting physisorption data for gas/solid systems with special reference to the determination of surface area and porosity. K.S.W. Sing, D.H. Everett, R.A.W. Haul, L. Moscou, R.A. Pierotti, J. Rouquerol, T. Siemieniewska

33. Kuwahara Y, Yamashita H (2015) Synthesis of Ca-based layered double hydroxide from blast furnace slag and its catalytic applications. ISIJ Int 55:1531-1537

34. Wanga J, Xing S, Huang Y, Fan P, Fu J, Yang G, Yang L, Lv P (2017) Highly stable gasified straw slag as a novel solid base catalyst for the effective synthesis of biodiesel: characteristics and performance. Appl Energy 190:703-712

35. Zhang YJ, Chai Q (2014) Alkali-activated blast furnace slag-based nanomaterial as a novel catalyst for synthesis of hydrogen fuel. Fuel 115:84-87

36. Bridgwater AV (2012) Review of fast pyrolysis of biomass and product upgrading. Biomass Bioenergy 38:68-94

37. Wang S, Dai G, Luo HYang,Zh (2017) Lignocellulosic biomass pyrolysis mechanism: a state-of-the-art review. Prog Energy Combust Sci 62:33-86

38. Gao N, Li A, Quan C, Du L, Duan Y (2013) TG-FTIR and PyGC/MS analysis on pyrolysis and combustion of pine sawdust. $\mathrm{J}$ Anal Appl Pyrol 100:26-32

39. Dhyani V, Bhaskar T (2018) A comprehensive review on the pyrolysis of lignocellulosic biomass. Renew Energy 129:695-716

Publisher's Note Springer Nature remains neutral with regard to jurisdictional claims in published maps and institutional affiliations. 


\section{Affiliations}

Ekaterina Kholkina ${ }^{1} \cdot$ Narendra Kumar $^{1} \cdot$ Taina Ohra-aho $^{2} \cdot$ Juha Lehtonen $^{2} \cdot$ Christian Lindfors $^{2} \cdot$ Marcus Perula $^{3}$. Janne Peltonen ${ }^{3} \cdot$ Jarno Salonen $^{3} \cdot$ Dmitry Yu. Murzin ${ }^{1}{ }^{2}$

1 Process Chemistry Centre, Åbo Akademi University,

3 University of Turku, 20014 Turku, Finland 20500 Turku/Åbo, Finland

2 VTT Technical Research Centre of Finland Ltd, 02150 Espoo, Finland 